\title{
Lung Cancer Mortality and Radon Concentration in a Chronically Exposed Neighborhood in Chihuahua, Mexico: A Geospatial Analysis
}

\author{
Octavio R. Hinojosa de la Garza, ${ }^{1,2}$ Luz H. Sanín, ${ }^{3}$ María Elena Montero Cabrera, \\ Korina Ivette Serrano Ramirez, ${ }^{3}$ Enrique Martínez Meyer, ${ }^{4}$ and Manuel Reyes Cortés ${ }^{2}$ \\ ${ }^{1}$ Centro de Investigación en Materiales Avanzados S.C., Complejo Industrial Chihuahua, Avenida Miguel de Cervantes 120, \\ 31109 Chihuahua, CHIH, Mexico \\ ${ }^{2}$ Facultad de Ingeniería, Universidad Autónoma de Chihuahua, Circuito Universitario Campus II, 31240 Chihuahua, CHIH, Mexico \\ ${ }^{3}$ Facultad de Enfermería y Nutriología, Universidad Autónoma de Chihuahua, Circuito Universitario Campus II, \\ 31240 Chihuahua, CHIH, Mexico \\ ${ }^{4}$ Instituto de Biología, Universidad Autónoma de México, Ciudad Universitaria, A.P. 70-233, 4510 Mexico DF, Mexico
}

Correspondence should be addressed to María Elena Montero Cabrera; elena.montero@cimav.edu.mx

Received 3 March 2014; Revised 24 May 2014; Accepted 9 June 2014; Published 6 August 2014

Academic Editor: Cristina Bosetti

Copyright (C) 2014 Octavio R. Hinojosa de la Garza et al. This is an open access article distributed under the Creative Commons Attribution License, which permits unrestricted use, distribution, and reproduction in any medium, provided the original work is properly cited.

\begin{abstract}
This study correlated lung cancer (LC) mortality with statistical data obtained from government public databases. In order to asses a relationship between LC deaths and radon accumulation in dwellings, indoor radon concentrations were measured with passive detectors randomly distributed in Chihuahua City. Kriging (K) and Inverse-Distance Weighting (IDW) spatial interpolations were carried out. Deaths were georeferenced and Moran's $I$ correlation coefficients were calculated. The mean values (over $n=171)$ of the interpolation of radon concentrations of deceased's dwellings were 247.8 and $217.1 \mathrm{~Bq} / \mathrm{m}^{3}$, for K and IDW, respectively. Through the Moran's $I$ values obtained, correspondingly equal to 0.56 and 0.61 , it was evident that LC mortality was directly associated with locations with high levels of radon, considering a stable population for more than 25 years, suggesting spatial clustering of LC deaths due to indoor radon concentrations.
\end{abstract}

\section{Introduction}

Lung Cancer (LC) has been characterized as a serious global public health issue with a high mortality rate. Based on the figures of the GLOBOCAN project, until 2008, LC had an incidence of $1,608,000$ new cases each year $(12.7 \%$ of all new cancer cases); moreover, this tumor was more common among men with $1,092,000$ cases, (16.5\% of the total) and 516,000 cases $(8.5 \%)$ among women [1].

Smoking habits are the main cause for the development of LC, according to the World Health Organization [2]; smoking increases between 5 to 10 times the risk of LC. In developing countries $80 \%$ of LC related deaths are attributable to tobacco consumption [3-5].

There is a controversy about whether there is an association between smoking and the effects of radon. Nonetheless, radon inhalation is considered the second risk factor for the development of LC [4-10].

Radon is a radioactive element, colorless, odorless, of natural origin, occurring in rocks and soil. This element results of two successive radioactive decays: initially uranium ${ }^{238} \mathrm{U}$ decays producing radium ${ }^{226} \mathrm{Ra}$ and this turns into radon ${ }^{222} \mathrm{Rn}$. Radon continues to disintegrate producing three elements-polonium, lead, and bismuth-known as the progeny of radon [11]. The nuclear decay continues until it forms a stable and nonradioactive progeny. During this process, the release of alpha, beta, and gamma radiation takes place. If radon and its progeny are inhaled, alpha particles can easily reach the epithelia cells in the lungs causing alterations to their DNA $[12,13]$. Continued exposure to radon increases and/or potentiates the risk of LC, which, according to the USA National Cancer Institute [14], is the only type of cancer 
associated with the inhalation of radon. According to WHO, LC exhibits a latency period around 25 years and it is worthy of mentioning that radon causes $15 \%$ of the cases of LC worldwide [3].

The city of Chihuahua is located near Mexico's main uranium ores. This situation, together with the igneous rock substrate of the region, makes uranium concentration in the ground an assumed source of radon emanation [15-17].

The National Survey of Addictions in 2011 (ENA-2011) [18] established that Chihuahua and Ciudad Juarez, both cities in Chihuahua state, have an active consumption of tobacco among people of $12-65$ years of age of $24.4 \%$, a higher consumption when compared with the national prevalence of $21.7 \%$. As a reference the ENA-2008 [19] reported a $27.6 \%$ prevalence of tobacco consumption among people of $18-65$ years of age in the state of Chihuahua and a $20.6 \%$ national prevalence. Historically, the LC mortality rates in Chihuahua City have been the double of those of Ciudad Juarez [17], which suggests the existence of another risk factor in addition to consumption of tobacco for LC deaths.

Atmospheric suspended particles, ranked by diameter, can deposit into the lungs; therefore inhaling them is recognized as a potential source of serious lung diseases. Decay products of radon are solid and are easily adsorbed by atmospheric particles. In particular, the climatic characteristics of Chihuahua contribute to the occurrence of suspended particles with diameters below 10 microns and coupled to that, during winter the accumulation of indoor gases is anticipated due to poorly ventilated homes.

In Mexico, geographical information systems (GIS) have been rarely implemented to monitor spatial assessments in cancer mortality. Nevertheless, recently it has been possible to obtain the database from Mexican Secretary of Health with detailed address information of death cases by different causes. Such information permits application of GIS [2024]. This source of information revealed that in 2010 the LC mortality rate in Chihuahua City was $2.4 \times$ and $2 \times$ greater than the national and that of Ciudad Juarez, respectively. Note that this information is given for each 100,000 inhabitants per year from 2004 to 2010 .

The aim of this work was to observe the evolution of LC mortality rate in the city of Chihuahua in comparison to the national mortality rate and thus relate geographically LC deaths with the occurrence of radon.

\section{Materials and Methods}

This research was conducted in Chihuahua City, in two phases. On the first, an epidemiological analysis of mortality data was conducted (2004-2010), to compare the frequency of occurrence of LC cases in the population throughout the country versus the Chihuahua state and the cities of Chihuahua and Ciudad Juarez. In the second phase, Chihuahua City was selected for a detailed inspection, based on the data from previous studies $[17,25]$ and the results of the first phase. Indoor radon concentrations were measured with passive detectors randomly distributed in Chihuahua City, as part of this phase. A Geographic Information System (ArcGis) was used to perform spatial geographic analysis of estimation about the distribution of deaths due to LC, searching for spatial clusters that may be associated with the inhalation of radon through the estimation of its air concentration indoors. In both phases, criteria used to verify information reliability are described in the "criteria" section.

\subsection{Phase 1}

2.1.1. Mortality Data. Mortality data used in this research was generated by the Secretaria de Salud de Chihuahua (Chihuahua health institute), [26]. An ecological design was applied [27]. Data from certificates for LC deaths that occurred in Chihuahua City during the period 2004-2010 were examined; this data has been encoded and validated by qualified personnel according to the rules of the 10th International Classification of Diseases [2] of the World Health Organization.

2.1.2. Criteria. Deaths classified as C349 were identified in the database. The consistency between the classifications was analyzed. In order to perform the analysis, once the suitable cases are selected, only the segment of population older than 30 years old was chosen and classified by age, sex, year of death, and geographic location.

Annual death rates were obtained per each 100,000 inhabitants for the period (2004-2010), and a comparison was made between the rates of the state of Chihuahua and the cities of Ciudad Juarez and Chihuahua with national results.

2.2. Phase 2. Chihuahua City was chosen to investigate possible correlations between radon exposure and death rates for LC cause as result of Phase 1.

To setup the spatial database, the exact location of the residence address as stated in the death certificate was located. For this purpose, the cartographic product "2009 Economic Census, DENUE March 2011" [28], the online digital urban map [29], and the ROJI maps guide of Chihuahua City [30] were used. All of them include the number of household and street name (spatially referenced). For a second validation, Google Maps technology was used: once the household was located, the street view was used to verify the number and street name with Google Earth. The neighborhoods limits in Chihuahua City were defined with this software. The study area has $224 \mathrm{~km}^{2}$, with a population of 572843 inhabitants [31].

2.2.1. Criteria. The households that did not meet the exact location (neighborhood, address, or street number) were discarded from the spatial analysis.

2.3. Radon Concentration Assessment. Radon concentrations were measured in previously randomly selected houses, along the city of Chihuahua, from 2010 to 2012, during winter season only. Canisters were distributed among students of Universidad Autonoma de Chihuahua, Centro de Investigacion de Materiales Avanzados and the Instituto Tecnologico de Chihuahua, which are educational institutions. Students' 
dwellings are located in different sectors of the city with different socioeconomic levels.

As reference for data control, the protocol of the US Environmental Protection Agency (EPA) 520/5-87-005 [32] was used.

Detectors:

(i) passive detector ID and place where it was located,

(ii) initial and final weight,

(iii) date and time of beginning and end of exposure at dwelling,

(iv) date and time of radioactivity measurement,

(v) measurement time.

Detector placement:

(i) lower level, master bedroom,

(ii) placed at bed level,

(iii) no heating,

(iv) away from window and water sources.

In order to determine the indoor air radon concentrations with passive detectors, diffusion barrier charcoal canisters (DBCC) were used. The radon activity concentration in a single room was determined by using DBCC during 4 days, measuring its adsorbed radon activity and dividing the result by a calibration function reported in [33]. Radon activity was determined by measuring gamma spectra from a certified source, a blank canister, and the corresponding exposed DBCC.

Radon concentrations of the sampling were georeferenced, and contour maps for Chihuahua City were generated using interpolation techniques. The assigned values to LC death locations were calculated with a weighted average of the values available at the radon concentration measurement points. Two common techniques were applied: log-normal Kriging $(\mathrm{K})$ interpolation (the weighted average of the measured values, having the minimum variance, is the value assigned to the LC location), according to the methodology described by Zhu et al. [34] and Buttafuoco et al. [35]; and inverse-distance weighting (IDW) interpolation, using the power factor 2 (weight decreases as the square of distance from the radon measurement points increases) [36].

The "outliers" or atypical values in radon concentrations were considered carefully using methods based on the standard deviation. Any measured value out of the range (smaller or greater than the resulting limits) was discarded [37].

These geographical statistical procedures generate an estimated surface area based on a scattered set of points with radon concentration values of the indoor air. Thus, values can be estimated in areas where no measurements are taken, and a map of radon concentration for Chihuahua City was generated. The corresponding interpolated in the map radon concentration values were added to the spatial database of LC deaths for each of the household addresses. To each of the georeferenced deaths, estimated radon concentrations to which the person was exposed were assigned.
To estimate those dwell residential times, the historical growing urban areas in Chihuahua City were spatially delimited for years 1920, 1921-1930, 1931-1969, 1970-1981, 19821993, and 1994-2012, using the geographic layers from the National Statistics and Geography Institute (INEGI) [38]. This information allowed the establishing of a reasonable time of LC latency for areas within the city and the verifying of the possibility of a cluster for the visually analyzed areas.

2.4. Data Analysis. ArcGis statistical package was used for spatial clustering search. To identify and measure auto-correlations in both models, the estimated values of radon concentration were introduced for each of the LC death addresses. The association between radon concentrations and LC death cases (through estimating the dispersion) was obtained by calculating the Moran's $I$ index $[39,40]$ (see Appendix A). Moran's $I$ index values vary between +1 and -1 . The first value means a perfect positive correlation, the second one-a perfect negative correlation, and the zero represents a completely random spatial pattern. It was verified if these clusters met the criteria of the 25-year latency by visually reviewing the map of historical growth.

Finally, a risk exposure by radon inhalation classification was obtained and represented. In order to unify criteria, a consensus map was produced by averaging the value of interpolations IDW and Kriging. The geostatistical basic area units (AGEB) of INEGI were used to quantify the urban population by block. AGEB was optimal for zoning, looking for homogeneity in distribution, concentration, density, or centralization of the population in a metropolitan area [41].

According to radon concentrations, a risk exposure classification was suggested, considering four categories: low (0$\left.74 \mathrm{~Bq} / \mathrm{m}^{3}\right)$, medium $\left(74-222 \mathrm{~Bq} / \mathrm{m}^{3}\right)$ high $\left(222-370 \mathrm{~Bq} / \mathrm{m}^{3}\right)$, and very high risk $>370 \mathrm{~Bq} / \mathrm{m}^{3}$ ) for visual representation of information, unifying EPA and working group criteria for this area $[42,43]$.

The process of integration of the entire methodology is described in a flowchart (Figure 1).

\section{Results}

During the period of 2004-2010 within the state of Chihuahua, LC cases were $n=2499$, of which 1442 were men, 699 were women, and 358 showed no gender data. The mortality rate for the population of Chihuahua City increased in 1.3\% (14.08\% in 2004 and $14.27 \%$ in 2010), whereas in Ciudad Juarez it increased in $10 \%$ (6.7\% in 2004 and $7.3 \%$ in 2010). In this context, the national LC mortality rate followed a low trend, decreasing in $9 \%$ (6.6\% in 2004 and 6\% in 2010; see Table 1).

The standardized mortality rate per LC 2010 in the city of Chihuahua was $2 \times$ greater than in Cd Juarez (which has twice the population of Chihuahua) and $2.4 \mathrm{x}$ greater than in México.

The largest number of LC deaths $(n=727)$, classified by age group, is in Chihuahua City. These defunctions are distributed as follows: $8 \%<50$ years, 50 years $\leq 22 \% \leq 65$ years, and $70 \%>65$ years (Table 2). Within these cases, 171 met all the criteria for spatial analysis (23\%). The selection process for LC death addresses is presented in Appendix B. 


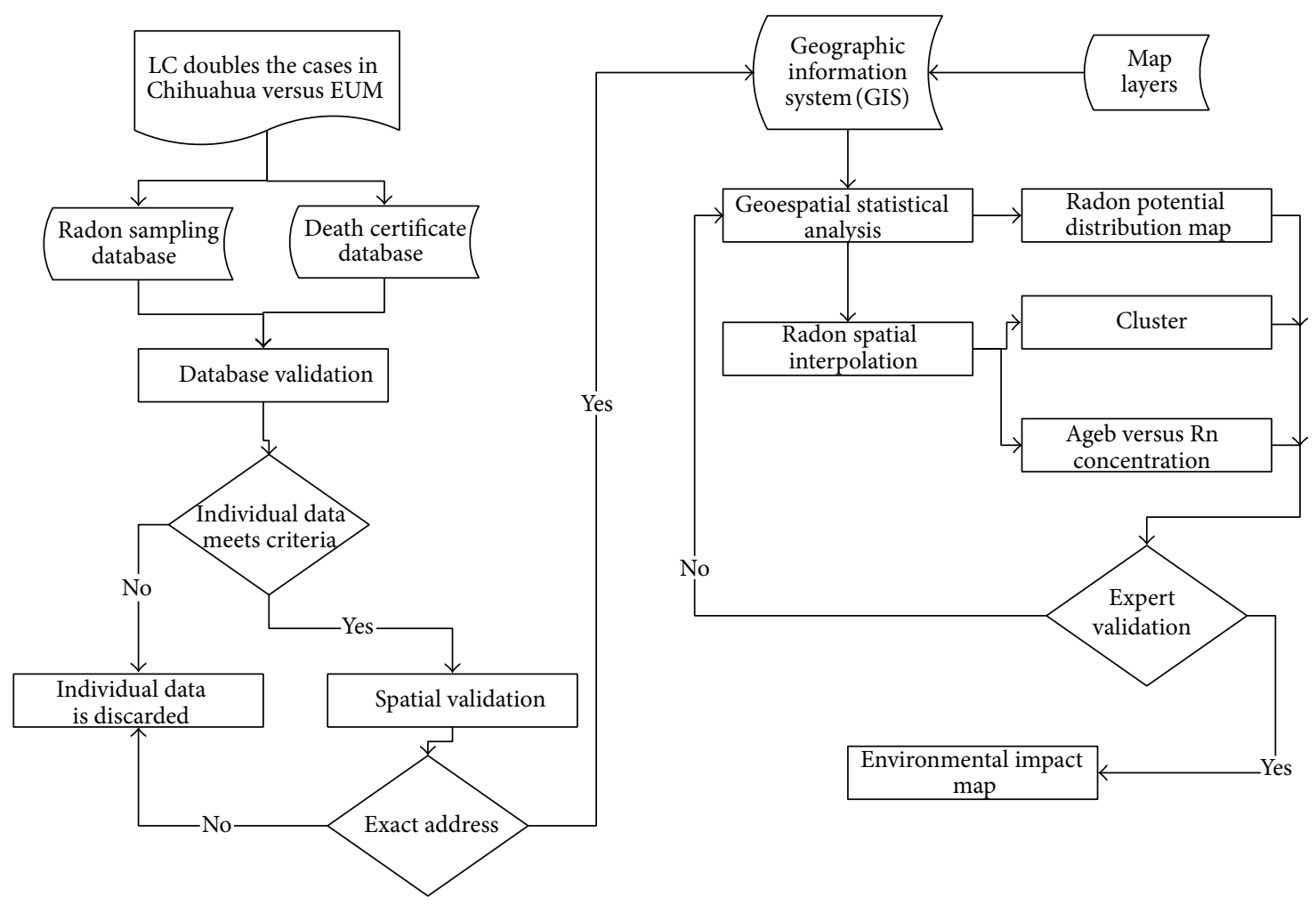

FIGURE 1: Working flowchart for the analysis of the databases. The criteria and methodology applied are described in the corresponding unit.

TABle 1: LC mortality rates of Chihuahua City, Ciudad Juarez, and México.

\begin{tabular}{cccc}
\hline Year & Chihuahua & Juarez & México \\
\hline 2004 & 14.1 & 6.7 & 6.6 \\
2005 & 11.3 & 8 & 6.8 \\
2006 & 14.8 & 7.1 & 6.5 \\
2007 & 13.6 & 6.8 & 6.3 \\
2008 & 13.1 & 6.1 & 6.3 \\
2009 & 11.3 & 5.8 & 6.2 \\
2010 & 14.3 & 7.3 & 6 \\
\hline
\end{tabular}

Source: Secretary of Health/Directorate General of Health Information in Chihuahua. Estimates are based on Population Projections for México 20052030, CONAPO, II Population and Housing Census 2005, and the Population and Census 2010. LC: lung cancer. The mortality rate is given per 100000 persons.

Historic city growth analysis revealed that $83 \%$ of LC deaths are in specific areas of city between the years 1969 and 1981 (see Table 3, Figure 2).

The average indoor radon concentration, sampled with canisters, in Chihuahua City was $249 \mathrm{~Bq} / \mathrm{m}^{3}$, over $n=118$ (Appendix C) with a minimal value of 0.3 to a maximum value of $1931.3 \mathrm{~Bq} / \mathrm{m}^{3}$. Results of outliers' analysis of the 118 measurements indicated nine extreme values of radon concentration above $585 \mathrm{~Bq} / \mathrm{m}^{3}$. These values were not taken into account to generate radon concentration interpolation

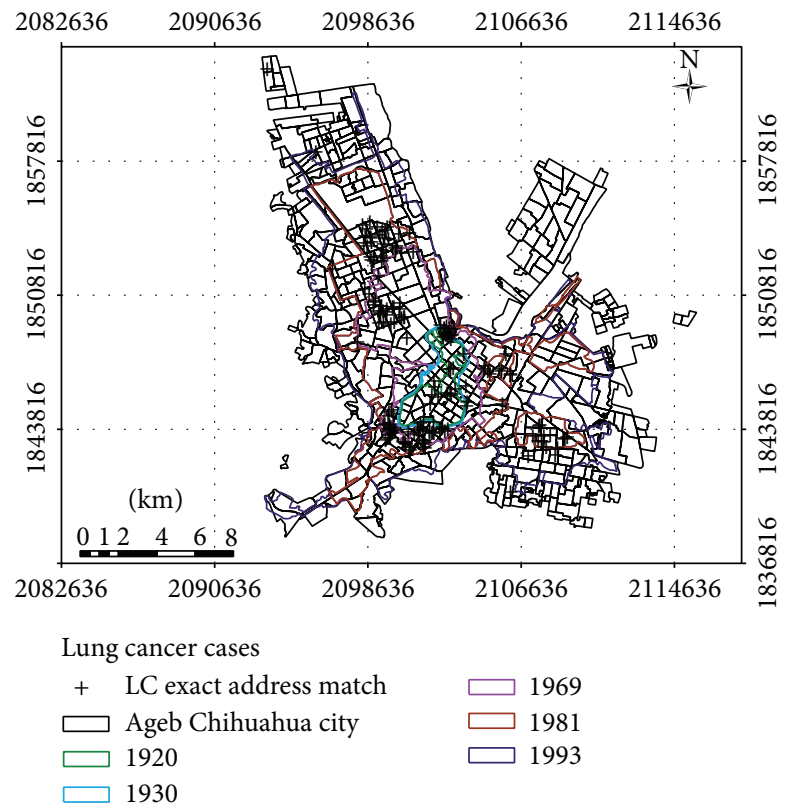

FIGURE 2: Historical growth of Chihuahua City versus LC deaths.

maps through Kriging and IDW techniques [37]. Thus, there were only $n=109$ values of radon activity concentrations taken as input for interpolations, with an average of radon concentration equal to $167.1 \mathrm{~Bq} / \mathrm{m}^{3}$, with a minimal value of 0.3 to a maximum value of $585 \mathrm{~Bq} / \mathrm{m}^{3}$. 
TABLE 2: Deaths by lung cancer as the underlying cause in Chihuahua City in population older than 25 years.

\begin{tabular}{|c|c|c|c|c|c|c|c|c|c|c|c|c|c|c|c|}
\hline \multirow{2}{*}{ Age } & \multicolumn{2}{|c|}{2004} & \multicolumn{2}{|c|}{2005} & \multicolumn{2}{|c|}{2006} & \multicolumn{2}{|c|}{2007} & \multicolumn{2}{|c|}{2008} & \multicolumn{2}{|c|}{2009} & \multicolumn{2}{|c|}{2010} & \multirow{2}{*}{ Tota } \\
\hline & M & $\mathrm{F}$ & $\mathrm{M}$ & $\mathrm{F}$ & $\mathrm{M}$ & F & $\mathrm{M}$ & $\mathrm{F}$ & $\mathrm{M}$ & $\mathrm{F}$ & $\mathrm{M}$ & $\mathrm{F}$ & M & F & \\
\hline $25-29$ & 1 & 0 & 0 & 0 & 0 & 0 & 0 & 0 & 0 & 0 & 0 & 0 & 0 & 1 & 2 \\
\hline $30-34$ & 0 & 0 & 2 & 0 & 0 & 1 & 1 & 1 & 0 & 0 & 0 & 0 & 0 & 0 & 5 \\
\hline $35-39$ & 1 & 0 & 0 & 0 & 1 & 0 & 0 & 0 & 1 & 1 & 1 & 0 & 0 & 1 & 6 \\
\hline $40-44$ & 3 & 1 & 2 & 1 & 4 & 0 & 2 & 0 & 3 & 0 & 3 & 1 & 4 & 2 & 26 \\
\hline $45-49$ & 2 & 1 & 1 & 1 & 2 & 1 & 1 & 1 & 0 & 1 & 1 & 2 & 1 & 3 & 18 \\
\hline $50-54$ & 1 & 2 & 1 & 1 & 6 & 2 & 5 & 0 & 3 & 3 & 1 & 2 & 3 & 0 & 30 \\
\hline $55-59$ & 5 & 1 & 3 & 3 & 6 & 5 & 8 & 4 & 7 & 0 & 3 & 2 & 4 & 2 & 53 \\
\hline $60-64$ & 11 & 3 & 9 & 1 & 14 & 0 & 8 & 3 & 6 & 2 & 6 & 5 & 7 & 4 & 79 \\
\hline $65-69$ & 9 & 5 & 9 & 7 & 16 & 9 & 10 & 2 & 13 & 7 & 5 & 3 & 13 & 5 & 113 \\
\hline $70-74$ & 13 & 8 & 13 & 6 & 5 & 4 & 13 & 8 & 21 & 6 & 10 & 6 & 10 & 5 & 128 \\
\hline $75-79$ & 16 & 10 & 10 & 4 & 16 & 4 & 12 & 5 & 10 & 4 & 13 & 6 & 19 & 5 & 134 \\
\hline $80-84$ & 7 & 2 & 3 & 4 & 4 & 5 & 10 & 8 & 7 & 6 & 11 & 1 & 8 & 6 & 82 \\
\hline $85-89$ & 1 & 1 & 1 & 2 & 3 & 2 & 3 & 1 & 3 & 0 & 4 & 2 & 5 & 3 & 31 \\
\hline $90-94$ & 1 & 1 & 0 & 2 & 2 & 2 & 0 & 0 & 0 & 0 & 3 & 0 & 2 & 3 & 16 \\
\hline 95-99 & 0 & 0 & 0 & 0 & 1 & 0 & 0 & 1 & 0 & 0 & 1 & 0 & 1 & 0 & 4 \\
\hline \multirow{2}{*}{ Total } & 71 & 35 & 54 & 32 & 80 & 35 & 73 & 34 & 74 & 30 & 62 & 30 & 77 & 40 & \\
\hline & \multicolumn{2}{|c|}{106} & \multicolumn{2}{|c|}{86} & \multicolumn{2}{|c|}{115} & \multicolumn{2}{|c|}{107} & \multicolumn{2}{|c|}{104} & \multicolumn{2}{|c|}{92} & \multicolumn{2}{|c|}{117} & 727 \\
\hline
\end{tabular}

Source: Secretary of Health/General Directorate of Health Information in Chihuahua. Estimates are based on Population Projections for México 2005-2030, CONAPO, II Population and Housing Census 2005, and the Population and Census 2010. Lung Cancer is classified by code C349. M: male; F: female.

TABLE 3: Historical growth of Chihuahua City versus $\mathrm{Bq} / \mathrm{m}^{3}$ estimates for deaths georeferenced.

\begin{tabular}{lcccc}
\hline Year & $N$ & $\mathrm{~Bq} / \mathrm{m}^{3}$ & Age of death (mean) & Age of death (min-max) \\
\hline $1920^{*}$ & 17 & $245 \pm 29$ & $66 \pm 16$ & $30-85$ \\
1930 & 4 & $256 \pm 43$ & $70 \pm 21$ & $39-84$ \\
1969 & 72 & $333 \pm 90$ & $69 \pm 13$ & $28-91$ \\
1981 & 70 & $257 \pm 57$ & $68 \pm 12$ & $34-92$ \\
1993 & 8 & $236 \pm 14$ & $64 \pm 15$ & $39-84$ \\
\hline
\end{tabular}

*Downtown.

Moran's I index was obtained for the two types of interpolation results of the radon concentration in LC death addresses. Moran's $I$ values were $0.61(P<0.01)$ for Kriging interpolation and $0.56(P<0.01)$ for IDW, respectively. The common area of the 2 maps was suggested as a cluster of LC deaths probably associated with high exposure to radon inhalation and it was delimited by a red circle (see Table 4 and Figure 3).

The number of LC cases, considering the four risk categories was: low ( 0 cases); medium $n=137$ deaths, mean radon concentration $=169.5 \pm 23 \mathrm{~Bq} / \mathrm{m}^{3}$; high $n=33$ deaths, mean radon concentration $=243.8 \pm 21 \mathrm{~Bq} / \mathrm{m}^{3}$; and very high risk $n=1$ death, mean radon concentration $=445.9 \mathrm{~Bq} / \mathrm{m}^{3}$.

The proposed cluster is characterized as follows: $n=28$, with 22 men with a mean age of $70.9 \pm 11.7$ (34-91 years) and 6 women with a mean age $70.5 \pm 8.9$ (34-91 years). The radon activity concentration interpolated by Kriging was $250 \pm 36$ $(178-392) \mathrm{Bq} / \mathrm{m}^{3}$ and IDW was $250 \pm 63(163-496) \mathrm{Bq} / \mathrm{m}^{3}$. These average values of radon activity concentrations correspond to the high exposure risk category.
TABLE 4: Spatial correlations.

\begin{tabular}{lc}
\hline Interpolation & Spatial autocorrelation $I$ Moran \\
\hline Kriging 109 & $I=0.61, Z=20.9, P=0.01$ \\
IDW 109 & $I=0.56, Z=19.85, P=0.01$ \\
\hline
\end{tabular}

The risk map of radon potential distribution was performed, assigning categories to the basic statistical units in Chihuahua City (AGEBs) [28] (see Table 5, Figure 4).

\section{Discussion}

In Chihuahua state LC death rates are higher than national rates and they show differences within the state territory. The rates show a great contrast when comparing among the populations of the two main cities (Ciudad Juarez and Chihuahua).

According to the national surveys of addictions from 2008 and 2011, in this ecological research we may conclude 

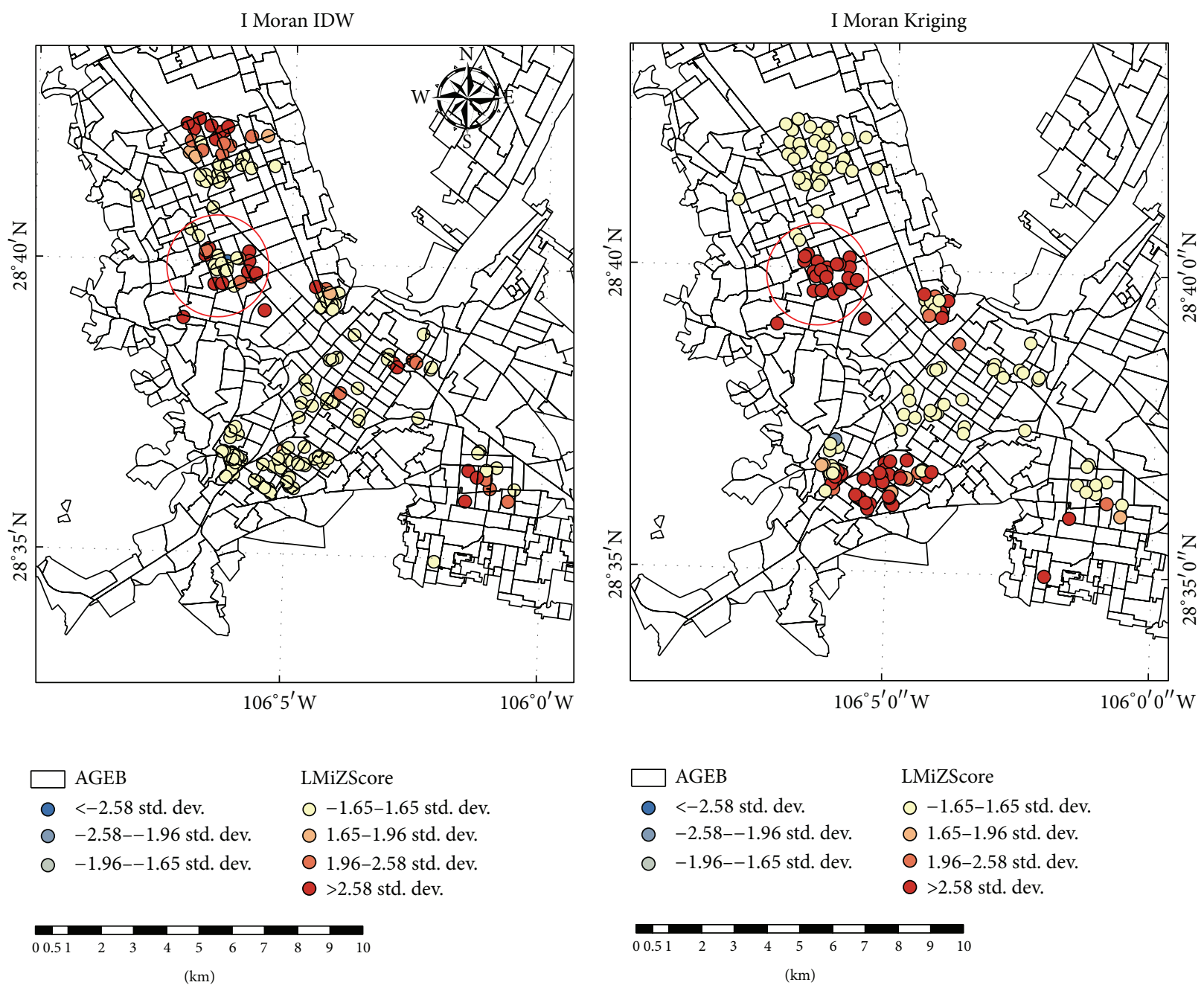

FIgURE 3: Cluster of LC deaths in Chihuahua City. LMiZScore means Local Moran Index Z score.

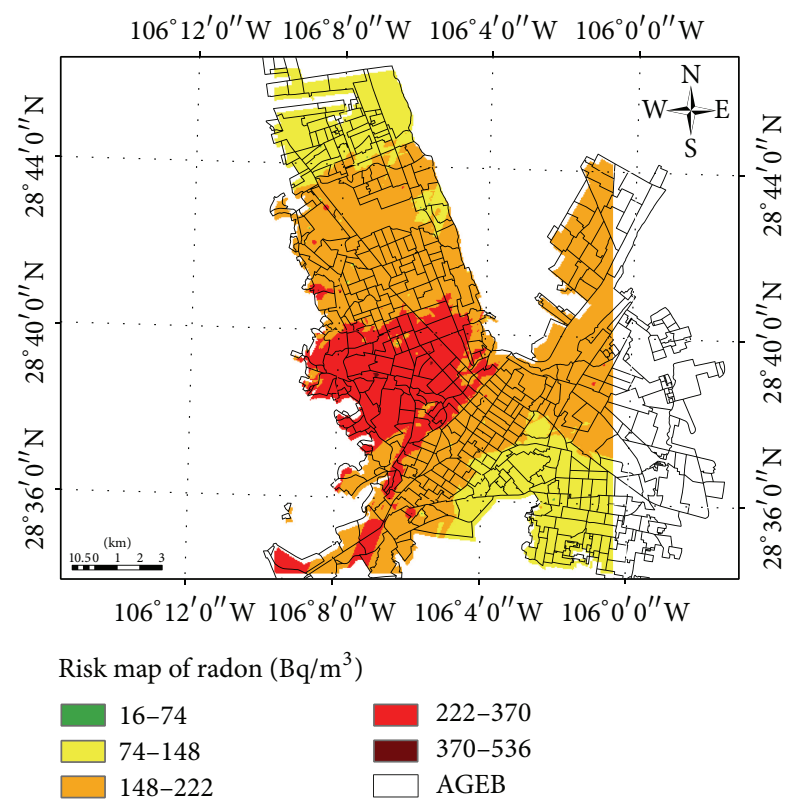

FIGURE 4: Radon exposure risk categories $\left(\mathrm{Bq} / \mathrm{m}^{3}\right)$ versus $\mathrm{AGEB}$ (total population).
TABLE 5: Radon exposure risk categories $\left(\mathrm{Bq} / \mathrm{m}^{3}\right)$ versus AGEB (total population).

\begin{tabular}{lccc}
\hline Description & Men & Women & Total \\
\hline Low risk $\left(4-74 \mathrm{~Bq} / \mathrm{m}^{3}\right)$ & 3443 & 3348 & 6791 \\
Medium risk $\left(74-148 \mathrm{~Bq} / \mathrm{m}^{3}\right)$ & 30358 & 31938 & 62296 \\
High risk $\left(148-370 \mathrm{~Bq} / \mathrm{m}^{3}\right)$ & 214089 & 224398 & 438487 \\
Very high risk $\left(>370 \mathrm{~Bq} / \mathrm{m}^{3}\right)$ & 67210 & 73537 & 140747 \\
\hline
\end{tabular}

Notice: the consensus map was used as a basis to quantify the population.

that no differences were found between the prevalence of tobacco consumption in the cities of Chihuahua and Ciudad Juarez. Tobacco is not considered a confounder but an independent predictor of LC. The number of LC deaths as the basic cause per age is the highest within the population over 65 years old in Chihuahua City. This is in agreement with other studies, which have encountered that the radon concentration in Chihuahua is higher than in Ciudad Juarez $[17,26]$.

The LC deaths in the GIS spatial database $(n=171)$ were mainly distributed into two historic areas of city growth. As 
a matter of fact, $42.1 \%$ of LC death cases were related to houses that were inhabited since 1969 , whereas $40.9 \%$ of the cases were located in residences built and occupied in 1981.

Moran's $I$ indexes obtained, well above zero for both interpolation methods, rule out the hypothesis of randomness, thus confirming the presence of a structural spatial dependence (depending on the distance). The cluster of LC deaths with significant high values $(P<0.01)$ is located in the North of the city and is represented with a red circle in the area of overlapping of the two maps generated (Moran's $I$ versus Kriging or IDW). It is proposed as a cluster of LC deaths possibly associated with radon inhalation exposure. The estimated population living in this area is of 26,395 inhabitants: 12425 men and 13970 women.

It is the first time that this kind of spatial study is carried out in the city of Chihuahua, where high radon levels, as well as high rates of LC deaths, have been previously reported.

The risk map shows the potential distribution of radon. It is recommended as a tool for decision makers, which never must replace radon monitoring in dwellings through the use of active or passive detectors [43].

As a potential weakness to this research, the ecological fallacy has been considered [44]. The data used is valid within population levels, though they may vary at clinical level due to the habits of the individuals and genetic matters. One could argue that globally the association could be altered by the poor measurement to the response variable, which in this research was lung cancer. However, because this response is the result of an accurate histological diagnosis of high quality, it does not admit possible error. Therefore, it is considered that this association is not affected by performing an ecological measurement [45-47]. Other study limitation would be that the only information that exists about permanency of inhabitants in the cluster area is the one provided by the urban development authorities of the city of Chihuahua and the knowledge of the authorities of this article. This information allows us to affirm that the population was very stable up to 2010 , when the public safety issues in the state caused address changes. Because this event is recent, these movements do not affect the data presented.

The measurement of the concentration of radon using canisters during winter allows the verifying of the houses where accumulation of radon was present. However, in order to calculate doses it would be necessary to perform measurements during the whole year. As a result this study is able to reject the null hypothesis of the random grouping of $\mathrm{LC}$ and that there is a probability that radon inhalation is a cause.

It would be worth analyzing smoking as independent predictor to the exposure to radon. It is suggested to continue in this line of research to get more accurate measurements.

There are studies that have examined the relationship between cancer and radon in soil, groundwater, and air in Mexico, both indoors and outdoors, as part of geophysical studies and to estimate effective doses as a result of radon exposure but there are not any other documented clusters. This detection of radon has mainly been performed with solid-state nuclear track detectors (SSNTD) and with active detection devices based on silicon detectors or ionization chambers $[48,49]$.

\section{Conclusions}

The average value of indoor radon concentration in Chihuahua City was $249 \mathrm{~Bq} / \mathrm{m}^{3}$, with concentrations varying among $0.3-1931.3 \mathrm{~Bq} / \mathrm{m}^{3}$. Previous studies of indoors radon levels indicated an average of $136\left(\mathrm{~Bq} / \mathrm{m}^{3}\right)$ [17], and an evident increase was observed. After verifying that the LC death rate of Chihuahua City is $2 \times$ greater than the national average, a different methodology to analyze historical information of LC deaths was proposed. The geospatial association between LC and indoor radon concentrations in the proposed cluster has been statistically proven; and the technical foundation to prevent population exposure in different regions has been pointed out by using risk maps. Therefore, it is proposed to include radon mitigation actions in the local regulation of construction, coupled to compulsory monitoring and remediation in existing buildings throughout the city.

We recommend a mass media awareness campaign regarding the source and effects of radon and simple measurements to prevent its exposure and continuing with the current antismoking campaigns.

\section{Appendices}

\section{A. Moran's Index}

If a database contains a spatial representation of the information, the structure of this data is a model of spatial information [50]. The spatial autocorrelation (SA) is the mathematic demonstration of the concentration or dispersion of the values of a variable in a map. A spatial autocorrelation can be defined as "property of a set of data located on a geographical map showing a pattern of organization" [51]. The SA reflects the degree to which the value of a random variable $z_{i}$ in a geographical unit is similar to the value of another random value $z_{i}$ in neighboring geographic units. The present study analyzes the geographic distribution of a random variable radon concentration in homes and the variable deaths for LC localization.

A.1. Moran's Index. I Moran is a global statistic that shows the existence of local spatial agglomerations around greater or lower values of the mean of all observations, that is to say, verifies if the variables are grouped, scattered or have a random distribution [52-54]. This I Moran index verifies the null hypothesis, that is, that the radon data analyzed is a random sample obtained from one of the $n$ ! possible spatial distributions among the $n$ locations of deceased's homes or vice versa. The definitions are as follows [55]:

$$
\begin{array}{r}
I=\frac{n}{S_{0}} \frac{\sum_{i=1}^{n} \sum_{j=1}^{n} w_{i, j} z_{i} z_{j}}{\sum_{i=1}^{n} z_{i}^{2}} \\
S_{0}=\sum_{i=1}^{n} \sum_{j=1}^{n} w_{i, j}
\end{array}
$$




$$
z_{i}=\frac{I-E[I]}{\sqrt{V[I]}},
$$$$
\text { where } V[I]=E[I]^{2}-E[I]^{2}, \quad E[I]=-\frac{1}{n-1} \text {, }
$$

where $z_{i}$ is the deviation of the $i$-value of variable from its mean value $\left(x_{i}-\langle X\rangle\right), w_{i j}$ is the spatial weight between variable $i$ and $j, n$ is equal to the total number of variables, and $S_{0}$ is the sum of all spatial weights.

If the values in the data set tend to group spatially, namely, the high values of the variables studied are close spatially and the lower values are close to other low values (grouped values), the Moran index will be positive. When the high values "reject" territorially other high values and tend to be surrounded by low values, the index will be negative (scattered values). If the positive values of the "cross products" balance the negative values of "cross products", the index will be close to zero. The numerator is normalized by the variance in a way that the values oscillate between -1.0 and +1.0 . Therefore, the proximity of the index to the value zero means randomness in the spatial relation.

The calculation is made with specialized software that also provides values of $P$ that indicate if the differences with the randomness are statistically significant.

\section{B. Georeferencing Techniques Employed for Creating Lung Cancer Deaths Database}

Due to difficult access to individual blocks or lots, 49 addresses were eliminated from Chihuahua's lung cancer decease database.

Localization and georeference techniques were utilized on the 678 remaining addresses: Google Earth's Apis https:// developers.google.com/maps/?hl=es, Global Mapper y Arcgis. As a result it was possible to completely georeference 310 addresses; for the remaining 368 only the street address without the number was found (Figure 5).

However, when validating the 310 addresses with the 3 complete data (address number, street name, and neighborhood name) errors were found in the above mentioned databases. As a result we proceeded to validate one by one the existence of the address, looking the exact location with the minimum error possible.

With this manual validation, errors ranging from 5 to 822 meters were corrected for each of the addresses generated from the databases. Finally addresses where the exact number was not found were discarded. This procedure produced 171 addresses with an exact address match.

Figure 6 shows the addresses of deaths with verified data $(n=678)$ in the geostatistic units (AGEB). It was noticed that the most confirmed information was the "neighborhood" or "AGEB" and that only 171 deaths have verifiable information.

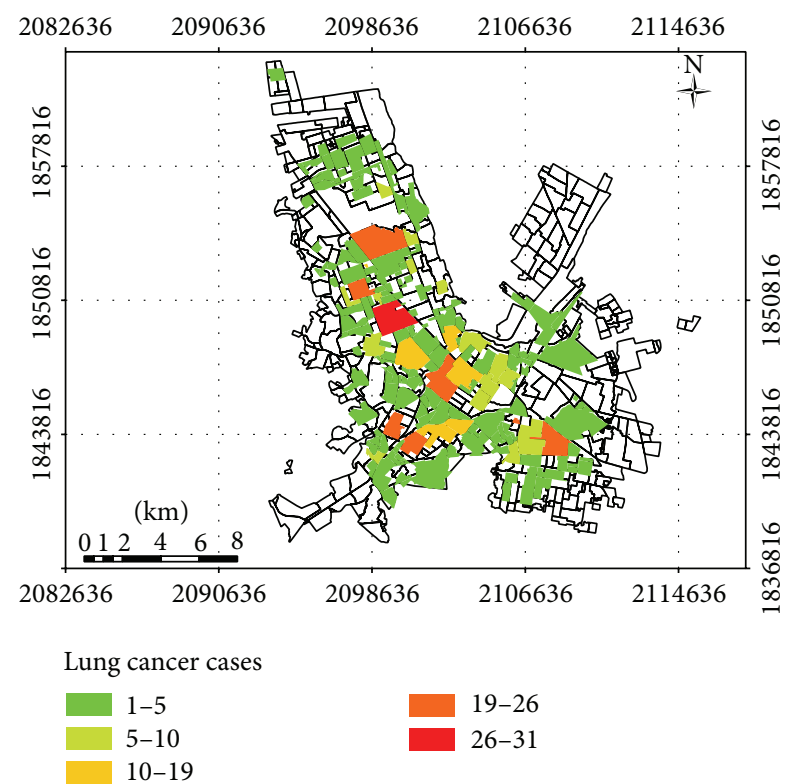

FIGURE 5: Chihuahua City map with the location of deaths by LC between 2004 and 2010. Lung cancer cases mean the number of deaths by neighborhood, according to the information provided by Secretary of Health. Colors allow appreciating the neighborhoods with more deaths by LC.

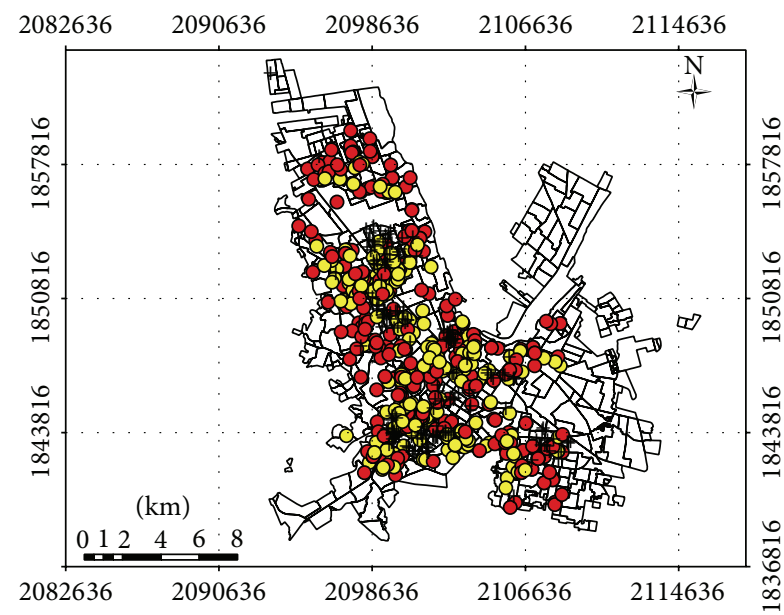

Lung cancer cases precision

o Address match + LC exact address match

- Street match

FIgure 6: LC death's address verification in Chihuahua City. The verified addresses are shown by the " + " symbol $(n=171)$; the home address that has a problem with some information is indicated in yellow and red circles $(n=139$ and $n=368)$.

\section{Indoor Radon Concentrations in Chihuahua City}

See Table 6. 
TABLE 6: Radon concentration values ( $\mathrm{RC}$ ), in $\mathrm{Bq} \mathrm{m}^{-3}$, obtained by measurements in random selected dwellings at Chihuahua City, Chihuahua, Mexico. $X$ and $Y$ are geographic longitude and latitude, respectively.

\begin{tabular}{|c|c|c|}
\hline $\mathrm{RC}$ & $X$ & $Y$ \\
\hline 150 & -106.143 & 28.689255 \\
\hline 203.5 & -106.121 & 28.738078 \\
\hline 264.1 & -106.134 & 28.683602 \\
\hline 87.99 & -106.143 & 28.692722 \\
\hline 159.5 & -106.15 & 28.692506 \\
\hline 134.9 & -106.15 & 28.655593 \\
\hline 236.4 & -106.12 & 28.677433 \\
\hline 504.1 & -106.1 & 28.595789 \\
\hline 274.2 & -106.11 & 28.726177 \\
\hline 132.5 & -106.13 & 28.748513 \\
\hline 185.4 & -106.1 & 28.719461 \\
\hline 128.5 & -106.13 & 28.7407 \\
\hline 693.1 & -106.09 & 28.634252 \\
\hline 299.6 & -106.02 & 28.649546 \\
\hline 205.8 & -106.01 & 28.657465 \\
\hline 1778 & -106.13 & 28.67081 \\
\hline 142.5 & -106.11 & 28.61914 \\
\hline 699 & -106.11 & 28.61914 \\
\hline 585 & -106.09 & 28.656286 \\
\hline 438.9 & -106.14 & 28.683809 \\
\hline 197.7 & -106.08 & 28.663992 \\
\hline 80.2 & -106.14 & 28.712529 \\
\hline 191.4 & -106.14 & 28.682457 \\
\hline 262.2 & -106.13 & 28.701008 \\
\hline 153.2 & -106.13 & 28.698289 \\
\hline 216.5 & -106.15 & 28.721249 \\
\hline 194.6 & -106.09 & 28.632977 \\
\hline 78.05 & -106.15 & 28.703597 \\
\hline 403 & -106.14 & 28.717492 \\
\hline 363.9 & -106.13 & 28.625798 \\
\hline 68.74 & -106.17 & 28.772309 \\
\hline 295.6 & -106.13 & 28.625798 \\
\hline 99.7 & -106.04 & 28.62749 \\
\hline 41.03 & -106.12 & 28.73795 \\
\hline 229.3 & -106.14 & 28.714763 \\
\hline 111.6 & -106.15 & 28.689209 \\
\hline 21.79 & -106.15 & 28.742 \\
\hline 33.21 & -106.15 & 28.71678 \\
\hline 94.14 & -106.11 & 28.61702 \\
\hline 161.1 & -106.08 & 28.651598 \\
\hline 91.36 & -106.092956 & 28.638554 \\
\hline 80.95 & -106.146391 & 28.64963 \\
\hline 151.67 & -106.040566 & 28.599516 \\
\hline 314.12 & -106.067193 & 28.643522 \\
\hline 133.81 & -106.091596 & 28.619658 \\
\hline 185.97 & -106.016807 & 28.652503 \\
\hline 197.28 & -106.118718 & 28.722543 \\
\hline 381.53 & -106.146998 & 28.703687 \\
\hline 55.62 & -106.044523 & 28.636603 \\
\hline 89.95 & -106.154496 & 28.593884 \\
\hline
\end{tabular}

TABLE 6: Continued.

\begin{tabular}{|c|c|c|}
\hline $\mathrm{RC}$ & $X$ & $Y$ \\
\hline 65.89 & -106.010599 & 28.670822 \\
\hline 186.93 & -106.113151 & 28.684938 \\
\hline 204.38 & -106.067193 & 28.643522 \\
\hline 147.85 & -106.067167 & 28.64439 \\
\hline 408.1 & -106.103371 & 28.682912 \\
\hline 28.39 & -106.103371 & 28.682912 \\
\hline 8.07 & -106.103371 & 28.682912 \\
\hline 14.19 & -106.103371 & 28.682912 \\
\hline 187.71 & -106.103371 & 28.682912 \\
\hline 44.71 & -106.103371 & 28.682912 \\
\hline 63.47 & -106.103371 & 28.682912 \\
\hline 4.65 & -106.103371 & 28.682912 \\
\hline 67.8 & -106.103371 & 28.682912 \\
\hline 52.01 & -106.103371 & 28.682912 \\
\hline 30.54 & -106.103371 & 28.682912 \\
\hline 40.98 & -106.103371 & 28.682912 \\
\hline 15.85 & -106.103371 & 28.682912 \\
\hline 195.77 & -106.090843 & 28.717466 \\
\hline 143.45 & -106.076983 & 28.649922 \\
\hline 515.22 & -106.09335 & 28.660756 \\
\hline 524.49 & -106.1174 & 28.651103 \\
\hline 69.32 & -106.067833 & 28.632944 \\
\hline 130.8 & -106.086342 & 28.61615 \\
\hline 28.39 & -106.094665 & 28.595761 \\
\hline 8.07 & -106.08248 & 28.623518 \\
\hline 14.19 & -106.1315 & 28.687614 \\
\hline 187.71 & -106.113949 & 28.707465 \\
\hline 4.65 & -106.129525 & 28.695041 \\
\hline 67.8 & -106.150203 & 28.736901 \\
\hline 52.01 & -106.09725 & 28.619133 \\
\hline 40.98 & -106.149393 & 28.709121 \\
\hline 15.85 & -106.144804 & 28.720217 \\
\hline 1931.28 & -106.09963 & 28.623148 \\
\hline 1782.98 & -106.142494 & 28.68847 \\
\hline 622.13 & -106.133314 & 28.693821 \\
\hline 149.96 & -106.142903 & 28.689255 \\
\hline 374.72 & -106.088075 & 28.663658 \\
\hline 93.64 & -106.103453 & 28.666872 \\
\hline 101.85 & -106.098758 & 28.659889 \\
\hline 251.35 & -106.107078 & 28.656819 \\
\hline 328.56 & -106.112906 & 28.669583 \\
\hline 394.27 & -106.105831 & 28.672308 \\
\hline 708.65 & -106.072947 & 28.666097 \\
\hline 195.77 & -106.090843 & 28.717466 \\
\hline 143.45 & -106.076983 & 28.649922 \\
\hline 515.22 & -106.09335 & 28.660756 \\
\hline 423.31 & -106.088845 & 28.635334 \\
\hline 524.49 & -106.1174 & 28.651103 \\
\hline 69.32 & -106.067833 & 28.632958 \\
\hline 130.8 & -106.086342 & 28.61615 \\
\hline 232.73 & -106.077064 & 28.709394 \\
\hline 137.62 & -106.010747 & 28.574078 \\
\hline 1862.73 & -106.145321 & 28.72253 \\
\hline
\end{tabular}


TABle 6: Continued.

\begin{tabular}{lcc}
\hline RC & $X$ & $Y$ \\
\hline 328.93 & -106.098631 & 28.623 \\
278.98 & -106.105603 & 28.614576 \\
180.56 & -106.010747 & 28.574078 \\
1147 & -106.032271 & 28.602279 \\
130.8 & -106.111032 & 28.675248 \\
129.38 & -106.014223 & 28.66454 \\
120.34 & -106.064356 & 28.663182 \\
117.62 & -106.091731 & 28.607276 \\
51.59 & -106.067816 & 28.674201 \\
50.12 & -106.067542 & 28.674784 \\
26.33 & -106.098946 & 28.718358 \\
26.33 & -106.058595 & 28.60697 \\
17.39 & -106.034878 & 28.602769 \\
5.58 & -106.095185 & 28.719983 \\
0.37 & -106.108291 & 28.663596 \\
\hline
\end{tabular}

\section{Conflict of Interests}

The authors declare that there is no conflict of interests regarding the publication of this paper.

\section{Acknowledgments}

The authors recognize the support of Servicio de Salud Gobierno del Estado de Chihuahua and Oliva Ramirez Fraire. They are thankful for the assistance given by Victor Hugo Ramos Sanchez. ORHG has developed this research under a CONACYT and CIMAV fellowship support.

\section{References}

[1] J. Ferlay, H. R. Shin, F. Bray, D. Forman, C. Mathers, and D. M. Parkin, GLOBOCAN 2008, Cancer Incidence and Mortality Worldwide, IARC Cancer Base No. 10, International Agency for Research on Cancer, Lyon, France, 2010.

[2] World Health Organization, International Statistical Classification of Diseases and Related Health Problems, World Health Organization, Lyon, France, 2004.

[3] World Health Organization, WHO Handbook on Indoor Radon: A Public Health Perspective, World Health Organization, Geneva, Switzerland, 2009.

[4] G. H. Rinker, E. J. Hahn, and M. K. Rayens, "Residential radon testing intentions, perceived radon severity, and tobacco use," Journal of Environmental Health, vol. 76, no. 6, pp. 42-47, 2014.

[5] P. M. Lantz, D. Mendez, and M. A. Philbert, "Radon, smoking, and lung cancer: the need to refocus radon control policy," The American Journal of Public Health, vol. 103, no. 3, pp. 443-447, 2013.

[6] T. Chahine, B. D. Schultz, V. G. Zartarian, J. Xue, S. V. Subramanian, and J. I. Levy, "Modeling joint exposures and health outcomes for cumulative risk assessment: the case of radon and smoking," International Journal of Environmental Research and Public Health, vol. 8, no. 9, pp. 3688-3711, 2011.

[7] W. J. Mccarthy, R. Meza, J. Jeon, and S. H. Moolgavkar, "Chapter 6: lung cancer in never smokers: epidemiology and risk prediction models," Risk Analysis, vol. 32, supplement 1, pp. S69-S84, 2012.
[8] M. C. Turner, D. Krewski, Y. Chen, C. A. Pope, S. M. Gapstur, and M. J. Thun, "Radon and nonrespiratory mortality in the American cancer society cohort," American Journal of Epidemiology, vol. 176, no. 9, pp. 808-814, 2012.

[9] Z. Zhang, J. Sun, J. Dong et al., "Residential radon and lung cancer risk: an updated meta-analysis of case-control studies," Asian Pacific Journal of Cancer Prevention, vol. 13, no. 6, pp. 2459-2465, 2012.

[10] National Research Council, BEIR Health Effects of Exposure to Radon-BEIR VI, National Academy Press, Washington, Wash, USA, 1999.

[11] C. Baird, Química Ambiental, Editorial Reverté, Barcelona, Spain, 2004.

[12] M. C. R. Alavanja, "Biologic damage resulting from exposure to tobacco smoke and from radon: implication for preventive interventions," Oncogene, vol. 21, no. 48, pp. 7365-7375, 2002.

[13] L. G. Ruipérez, El Radón y Sus Riesgos, Universidad de Oviedo, 1992.

[14] NCI, "Radon and Cancer," 2013, http://www.cancer.gov/cancertopics/types/lung.

[15] J. C. Burillo Montúfar, M. Reyes Cortés, I. A. Reyes Cortés et al., "Uranium-series isotopes transport in surface, vadose and ground waters at San Marcos uranium bearing basin, Chihuahua, Mexico," Applied Geochemistry, vol. 27, no. 6, pp. 11111122, 2012.

[16] M. Reyes-Cortés, L. Fuentes-Cobas, E. Torres-Moye, H. Esparza-Ponce, and M. E. Montero-Cabrera, "Uranium minerals from the San Marcos District, Chihuahua, Mexico," Mineralogy \& Petrology, vol. 99, no. 1-2, pp. 121-132, 2010.

[17] L. H. Colmenero Sujo, "Análisis de radionúclidos en suelos y de radón en domicilios de las principales ciudades del estado de Chihuahua," Centro de Investigación en Materiales Avanzados, Chihuahua, Mexico, 2004.

[18] J. Villatoro-Velázquez, M. E. Medina-Mora, C. Fleiz-Bautista et al., "Encuesta nacional de adicciones 2011," in Reporte de drogas. México, Instituto Nacional de Psiquiatría Ramón de la Fuente Muñiz, Tlalpan, Mexico, 2012.

[19] J. Villatoro-Velázquez and M. Medina-Mora, "Encuesta nacional de adicciones," in Reporte de Drogas, Instituto Nacional de Salud Pública, Cuernavaca, Mexico, 2008.

[20] A. Canoba, F. O. López, M. I. Arnaud et al., "Indoor radon measurements in six Latin American countries," Geofisica Internacional, vol. 41, no. 4, pp. 453-457, 2002.

[21] F. Franco-Marina, N. Segovia, W. Ruiz et al., "Short and long term indoor radon survey in Mexico City," Radiation Measurements, vol. 34, no. 1-6, pp. 545-548, 2001.

[22] G. Espinosa, A. Chavarria, and J. Golzarri, "A study of indoor radon in greenhouses in Mexico City, Mexico," Journal of Radioanalytical and Nuclear Chemistry, vol. 296, no. 1, pp. 37-41, 2013.

[23] N. A. H. Alonso, A. Kotsarenko, V. Yutsis et al., "Environmental and indoor study of Radon concentration in San Joaquin area, Queretaro, Mexico, first results," Radiation Measurements, vol. 50, pp. 149-153, 2013.

[24] F. Franco-Marina, J. Villalba-Caloca, N. Segovia, and L. Tavera, "Spatial indoor radon distribution in Mexico City," Science of the Total Environment, vol. 317, no. 1-3, pp. 91-103, 2003.

[25] M. E. M. Cabrera, L. C. Sujo, L. Villalba et al., "Rn-222 air concentrations in Chihuahua State (Mexico) dwellings and in the U.S./Mexico border," Microchemical Journal, vol. 81, no. 1, pp. 28-34, 2005. 
[26] Dirección General de Información en Salud, Sistema Epidemiológico y Estadístico de las Defunciones (SEED), 2010, http://www.sinais.salud.gob.mx/.

[27] V. H. Borja-Aburto, "Estudios ecológicos," Salud Pública de México, vol. 42, pp. 533-538, 2000.

[28] Instituto Nacional de Estadística y Geografía, "Cartografía Geoestadística Urbana-Localidad 080190001," in Censos Económicos, DENUE Marzo, 2009.

[29] INEGI, “Mapa Digital de Mexico," 2013, http://gaia.inegi.org $. \mathrm{mx} / \mathrm{mdm} 5 /$ viewer.html.

[30] J. Palacios Roji Garcia and A. Palacios Roji Garcia, Mapa de la ciudad de Chihuahua, Guia Roji, Mexico, 2012.

[31] INEGI, Censo General de Población y Vivienda, México, Instituto Nacional de Estadísticas y Geografía, Aguascalientes, Mexico, 2010.

[32] D. J. Gray and S. Windham, EERF Standard Operating Procedures for Radon-222 Measurement Using Charcoal Canisters, Eastern Environmental Radiation Facility, Environmental Protection Agency, 1987.

[33] M. E. Montero-Cabrera, L. Colmenero-Sujo, L. Villalba et al., "Calibration of diffusion barrier charcoal detectors using a semi-empirical expression," Applied Radiation and Isotopes, vol. 59, no. 4, pp. 281-287, 2003.

[34] H. C. Zhu, J. M. Charlet, and A. Poffijn, "Radon risk mapping in southern Belgium: an application of geostatistical and GIS techniques," Science of the Total Environment, vol. 272, no. 1-3, pp. 203-210, 2001.

[35] G. Buttafuoco, A. Tallarico, and G. Falcone, "Mapping soil gas radon concentration: a comparative study of geostatistical methods," Environmental Monitoring and Assessment, vol. 131, no. 1-3, pp. 135-151, 2007.

[36] E. H. Isaaks and R. M. Srivastava, Applied Geostatistics, Oxford University Press, New York, NY, USA, 1989.

[37] J. W. Tukey, Exploratory Data Analysis, Addison-Wesley, Reading, Mass, USA, 1977.

[38] INEGI, “Layer,” 2013, http://www.inegi.org.mx/geo/contenidos/ recnat/geologia/InfoEscala.aspx.

[39] P. A. P. Moran, “The interpretation of statistical maps," Journal of the Royal Statistical Society A, vol. 10, pp. 243-251, 1948.

[40] ARCGIS, "Spatial Autocorrelation (Global Moran's I)," 2013, http:// resources.arcgis.com/en/help/main/10.1/index.html\#/Spatial_ Autocorrelation_Global_Moran_s_I/005p0000000n000000/.

[41] INEGI, Cartografía Geoestadística Urbana 2011, Instituto Nacional de Estadística y Geografía (INEGI), 2011.

[42] S. Risica, "Legislation on radon concentration at home and at work," Radiation Protection Dosimetry, vol. 78, no. 1, pp. 15-21, 1998.

[43] EPA, Map of Radon Zones, 2013, http://www.epa.gov/radon/ zonemap.html.

[44] L. I. Langbein and A. J. Lichtman, Ecological Inference, Sage, Newbury Park, Calif, USA, 1978.

[45] O. Raaschou-Nielsen, "Indoor radon and childhood leukaemia," Radiation Protection Dosimetry, vol. 132, no. 2, pp. 175-181, 2008.

[46] R. Salway and J. Wakefield, "A hybrid model for reducing ecological bias," Biostatistics, vol. 9, no. 1, pp. 1-17, 2008.

[47] S. Haneuse and J. Wakefield, "Geographic-based ecological correlation studies using supplemental case-control data," Statistics in Medicine, vol. 27, no. 6, pp. 864-887, 2008.
[48] N. Segovia, M. I. Gaso, and M. A. Armienta, "Environmental radon studies in Mexico," Environmental Geochemistry and Health, vol. 29, no. 2, pp. 143-153, 2007.

[49] G. Espinosa, J. I. Golzarri, J. Bogard et al., "Indoor radon measurements in Mexico City," Radiation Measurements, vol. 43, supplement 1, pp. S431-S434, 2008.

[50] M. F. Goodchild, Spatial Autocorrelation, vol. 47, Geo Books Norwich, 1986.

[51] A. Getis and J. K. Ord, "The analysis of spatial association by use of distance statistics," Geographical Analysis, vol. 24, no. 3, pp. 189-206, 1992.

[52] L. Anselin, I. Syabri, and Y. Kho, "GeoDa: an introduction to spatial data analysis," Geographical Analysis, vol. 38, no. 1, pp. 5-22, 2006.

[53] L. Anselin, "Interactive techniques and exploratory spatial data analysis," in Geographical Information Systems: Principles, Techniques, Management and Applications, vol. 1, pp. 251-264, John Wiley \& Sons, New York, NY, USA, 1999.

[54] L. Anselin, "Local indicators of spatial association-LISA," Geographical Analysis, vol. 27, no. 2, pp. 93-115, 1995.

[55] A. Mitchel, he ESRI Guide to GIS Analysis, Volume 2: Spartial Measurements and Statistics, ESRI Guide to GIS Analysis, 2005. 


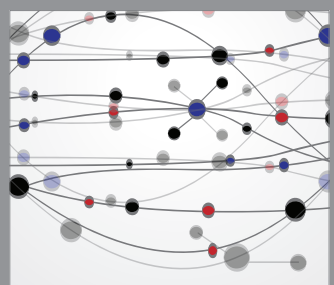

The Scientific World Journal
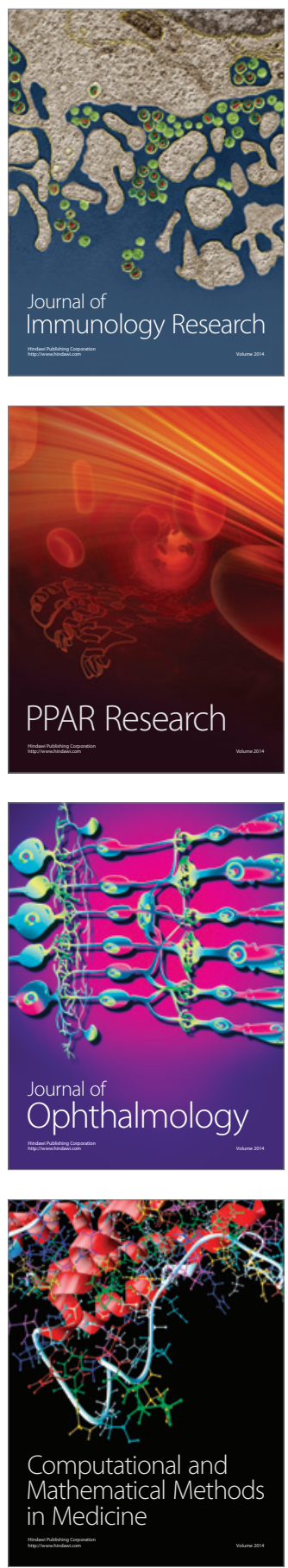

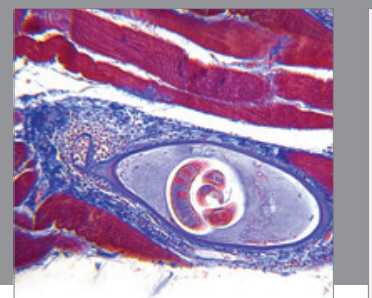

Gastroenterology

Research and Practice
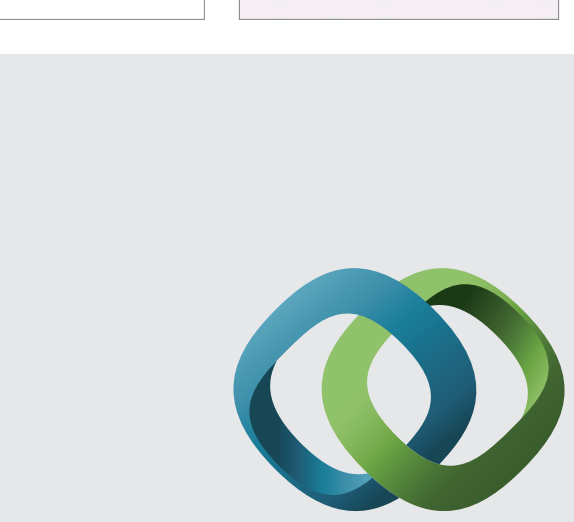

\section{Hindawi}

Submit your manuscripts at

http://www.hindawi.com
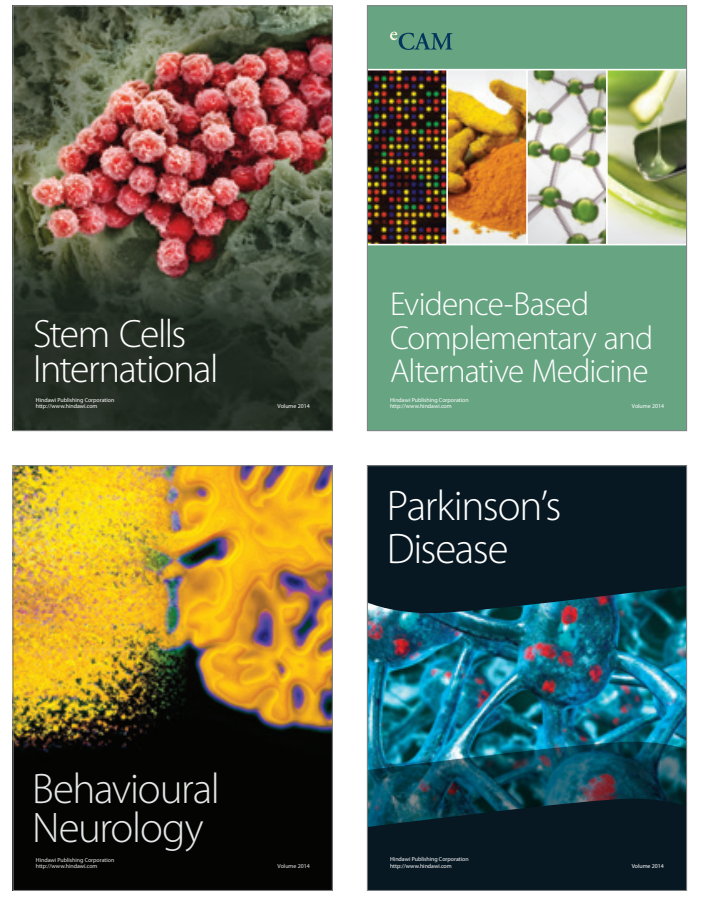
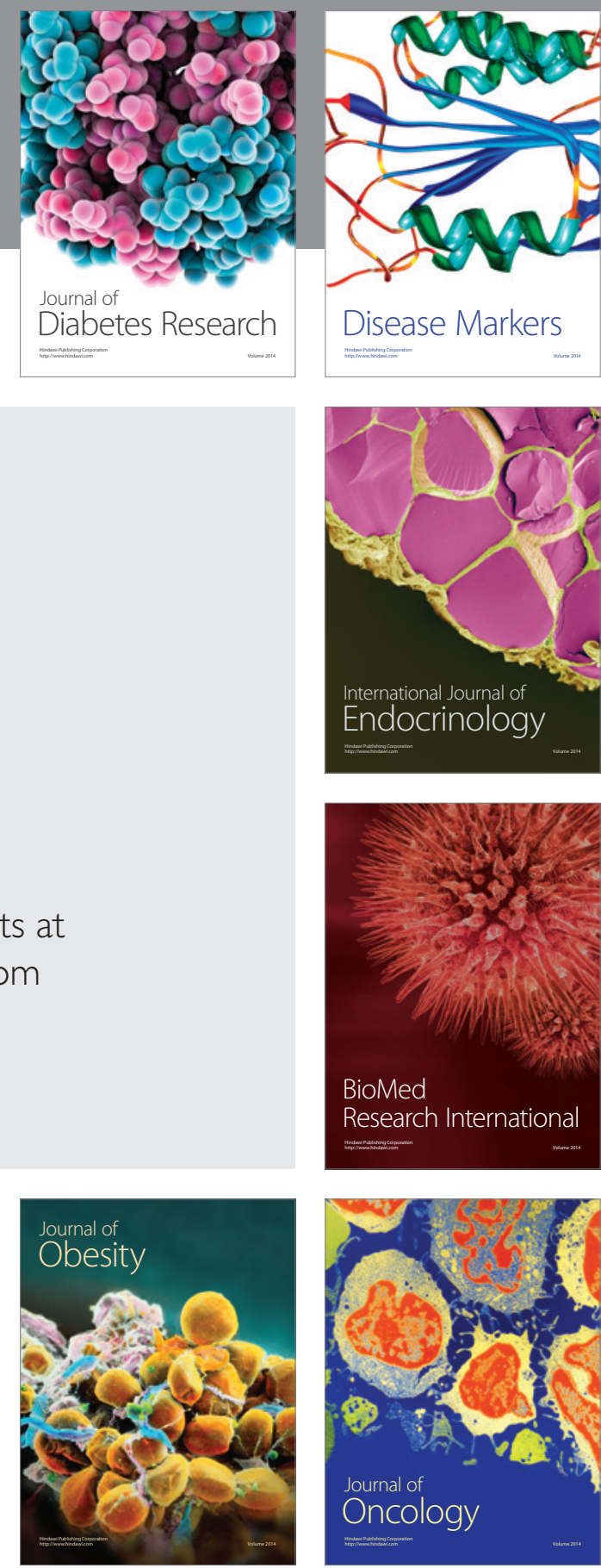

Disease Markers
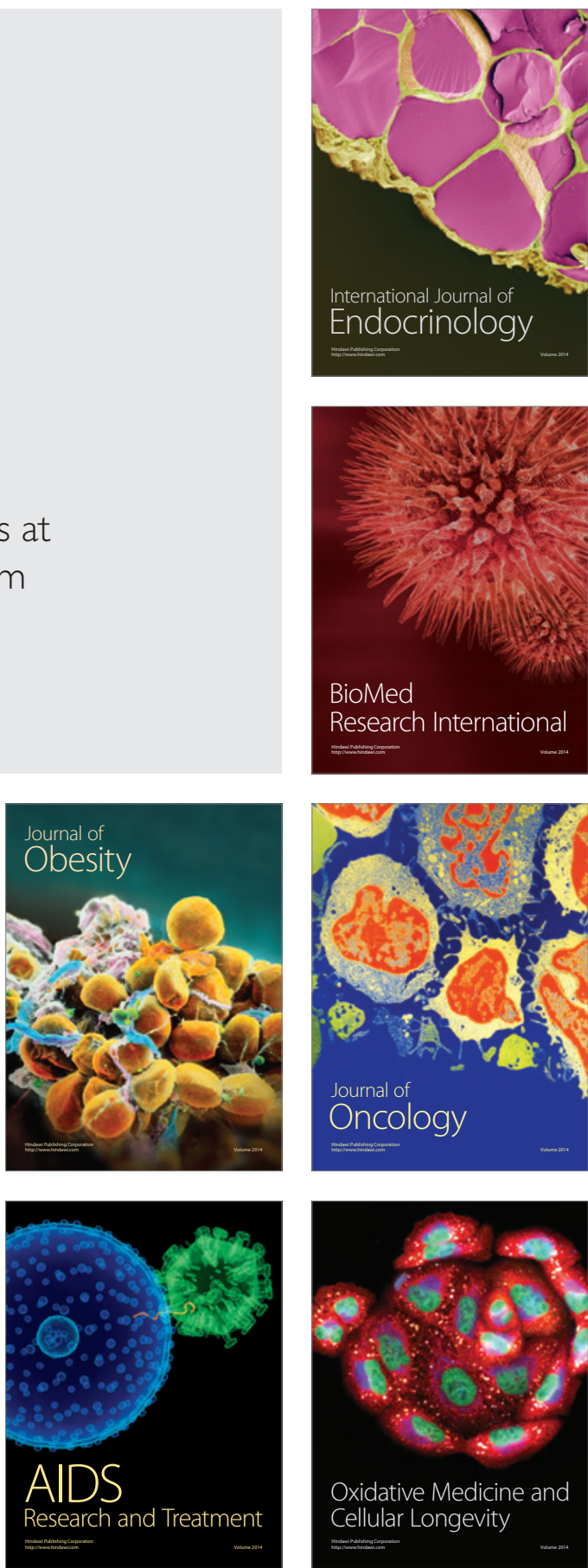